\title{
EFFECTIVENESS OF TRANSCUTANEOUS ELECTRICAL NERVE STIMULATION AND INTERFERENTIAL CURRENT IN PATIENTS WITH NON-SPECIFIC CHRONIC LOW BACK PAIN
}

\author{
Muhammad Adnan', Babar Ali², Muhammad Mohsin Sajjad³, Ali Rahman, Omair Rafiq Qurashi5, Haider Darain ${ }^{5}$ \\ 'Department of Health Sciences, City University of Science and Information Technology Peshawar \\ ${ }^{2}$ Physical Therapy Department, Abasyn University Peshawar \\ ${ }^{3}$ Neurology/Stroke Medicine, Royal College of Physicians Ireland \\ ${ }^{4}$ Physical Therapist, Paraplegic Centre Peshawar \\ ${ }^{5}$ Institute of Physical Medicine and Rehabilitation, Khyber Medical University, Peshawar
}

\begin{abstract}
Objectives: To compare the effectiveness of Transcutaneous Electrical Nerve Stimulation (TENS) and Interferential Current (IF) in patients with nonspecific chronic low back pain.

Material and Methods: This quasi experimental study was performed in Khyber Teaching Hospital and Khyber Medical University Peshawar from August 2015 to January 2016. All patients were assessed before and after TENS and IF therapy using Visual Analogue Scale 0-10 (VAS) and Oswestry Disability Index (ODI). Thirty patients were divided into two groups. TENS (group I) \& IF (group II). In group I, patients received 10 minutes session with heat therapy (hot pack) and 20 minutes session with TENS. In group II, the patients received 10 minutes session with heat therapy (hot pack) and 20 minutes session with IF current.

Results: Mean age of participants was $34.85 \pm 4.80$ and $33.50 \pm 5.20$ years in group I and group II respectully. The mean of pain before treatment in group I was $6.47 \pm .29$ and that of group II was $5.60 \pm .33$ in which the minimum pain on VAS was 4 and maximum pain was 8 . A pair T test was done to identify the difference between pre and post treatment score on VAS in the intervention. The $p$ values shows .000 which is less than .05 indicate that there is significant difference present between pre and post treatment pain on VAS. The pair T test for disability percentage on ODI was done to identify the difference between pre and post treatment in the interventions. The $p$ value was less than .05 which shows that there is significant difference and reduction of disability percentage on ODI. Conclusion: The study concluded that both the treatment methods TENS and IF are effective in decreasing pain intensity and disability in low back pain patients.
\end{abstract}

Keywords: Transcutaneous electrical nerve stimulation, Interferential current, Non-specific chronic low back pain.

This article may be cited as: Adnan M, Ali B, Sajjad MM, Rahman A, Qurashi OR, Darain H. Effectiveness of Transcutaneous Electrical Nerve Stimulation and Interferential Current in patients with non-specific chronic low back pain. J Med Sci 2020 October;28(4):341-344

\section{INTRODUCTION}

Low back pain (LBP) is a common condition that has been reported to affect many people of all ages every year ${ }^{1}$. The problem is evident from the fact that half of the world population, experience LBP during their life ${ }^{2}$.

\section{Correspondence}

Dr. Babar Ali

Coordinator, Physical Therapy Department Abasyn Uni-

versity, Peshawar - Pakistan.

Email: babar.ali@abasyn.edu.pk

Cell: +92-314-9009601

Date received: $15-11-2020$

Date revised: $\quad 01-12-2020$

Date accepted: $30-12-2020$
LBP has unfavorable effects on the peoples quality life, and influence on individuals everyday activities, physical health, mental health status and affects economic status of people ${ }^{3}$.

The modes of treatment for radiating and non-radiating low back pain are pharmacological and non-pharmacological ${ }^{4}$. Electrotherapy is a noninvasive and non-pharmacological mode of treatment ${ }^{5}$. Studies conducted so far haven't shown clearer that electrotherapy modality, TENS, produces better effects as far as the pain in the lower back is concerned. Fewer studies are available on the effectiveness of IF, TENS and heat therapy as an adjunct in patients with chronic LBP. Our study has focused on 
Effectiveness Of Transcutaneous Electrical Nerve Stimulation And Interferential Current In Patients With Non-Specific...

comparing the effectiveness of IF, TENS and heat therapy as conservative treatment in both groups in patients with nonspecific chronic LBP.

\section{MATERIAL AND METHODS}

A quasi experimental study was conducted in Khyber Teaching Hospital and Physiotherapy Clinic of Khyber Medical University, (KMU) Peshawar from August 2015 to January 2016 after ethical approval from Research Ethics Board of KMU. 30 patients were included in the study, (15 in each group). Males were $20(66.7 \%)$ and females were $10(33.3 \%)$. Convenient sampling technique was used for data collection. In the first group TENS therapy was used for treatment and in the second group IF current was used. Heat therapy was used as an adjunct to groups i-e TENS therapy and to IF current. Patients aged over 18 years and below 60 years of both gender, having chronic low back pain (more than three months) were included in the study. Female patients having pregnancy, history of recent surgery of the spine, (less than six months), patients who had contraindications to the use of electrotherapy, (such as skin lesions, sensitivity changes, infectious diseases, bleeding and cardiac pacemaker), those with psychiatric disorders and patients who did not wish to participate were excluded from the study.

The data was collected through VAS 0-10 and ODI scales. ${ }^{6,7}$ VAS was used for pain intensity and for functional ability ODI was used. These scales were used before and after the treatment sessions.

Portable TENS and device for IF current was used for treatment. The intensity of the current ranging from 0 to 80 milliamps (mA) was used. The four silicone self-adhesive electrodes pads, each $5 \times 5 \mathrm{~cm}$ were place on patient back in the line from T12 and S1 level of spinal cord. The TENS machine was placed to the patient's back at a frequency of $20 \mathrm{~Hz}$ and the pulse width of $330 \mathrm{~ms}$, with two channels of TENS. The IF Current was adjusted with a base frequency of $4000 \mathrm{~Hz}$, with a modulation frequency having range of $20 \mathrm{~Hz}$, and slope of $1 / 1$, in Quadripolar mode. ${ }^{8,9}$ For improving the inflow of current through the skin 10 minutes of heat therapy through hot pack was given to each patient in both groups. We used SPSS version 20 for data analysis and interpretation of results.

Patients were described about both treatment protocols and written consent form was taken. All patients were allowed to discontinue participation at any time and there was no risk to the patients participated in this study and at the end of the treatment session each patient has received a proper exercise plan for their home.

\section{RESULTS}

Total males were $20(66.7 \%)$, and total females were $10(33.3 \%)$. Cross tabulation showed that there were 9 males and 6 females in group one and 11 males and 4 females were in group two.

The ages of patients ranged from $34.85 \pm 4.80$ to $33.50 \pm 5.20$ with in group-I and group-ll. The common ages were from 30 to 40 . People involved in the study were having a diverse background of professions, which inluded housewives $(20 \%)$ and the reaming percentage was policemen, office workers, drivers, teachers, students and other professions.

\section{OCCUPATION CHART OF THE PATIENTS}

The mean pain on VAS before treatment in group I showed $6.47 \pm .29$ and that of group II was $5.60 \pm .33$ in which the minimum pain on VAS was 4 and maximum pain was 8 having $P$ value of 0.000 for group I and 0.001 for group II. The independent $T$ test shows $p$ value $>.05$ which determine no significant difference between each groups in pain on VAS before treatment. The disability percentage on ODI before treatment in group I showed a mean percentage of $42.66 \pm 10.11$, and disability percentage of group II was $38.40 \pm 3.00$ in which the minimum disability percentage was 18 and maximum pain was 64 . The independent $T$ test for disability percentage between groups showed a $p$ value of .295 which shows homogeneousness between each group.

A pair $\mathrm{T}$ test was done to identify the difference between pre and post treatment score on VAS in the intervention. The $p$ values shows .000 which is less than .05 which indicate that there is significant difference present between pre and post treatment pain on VAS. The pair T test for disability percentage on ODI was done to identify the difference between pre and post treatment percentage in the intervention. The $p$ value was less than .05 which shows that there is significant difference and reduction of disability percentage on ODI.

The following table shows that P-Vale in both cases is higher than 0.05 , which is not significant and indicates
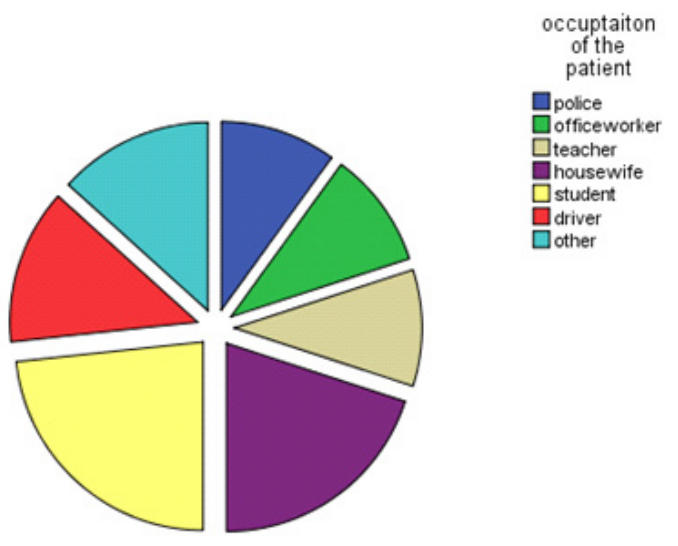

Fig 1: Occupation chart of the patients 
Effectiveness Of Transcutaneous Electrical Nerve Stimulation And Interferential Current In Patients With Non-Specific...

Table 1: Pre and post intervention comparison

Comparison between pre and post intervention for disability percentage and hip ROM (Parametric test)

\begin{tabular}{|c|c|c|c|c|}
\hline $\begin{array}{c}\text { Treatment } \\
\text { Groups }\end{array}$ & Variables & $\begin{array}{c}\text { Treatment } \\
\text { session }\end{array}$ & $\begin{array}{l}\text { Mean and } \\
\text { Std.Dev }\end{array}$ & Value \\
\hline \multirow{4}{*}{$\begin{array}{l}\text { TENS } \\
\text { Group }\end{array}$} & \multirow{2}{*}{$\begin{array}{l}\text { Pain on } \\
\text { VAS }\end{array}$} & Pre & $6.47+1.25$ & \multirow[t]{2}{*}{0.000} \\
\hline & & Post & $4.20+1.20$ & \\
\hline & \multirow{2}{*}{$\begin{array}{c}\text { Disability } \\
\text { on ODI }\end{array}$} & Pre & $42.66+10.1$ & \multirow[t]{2}{*}{0.000} \\
\hline & & Post & $18.80+4.64$ & \\
\hline \multirow[t]{4}{*}{ IF Group } & \multirow{2}{*}{$\begin{array}{l}\text { Pain on } \\
\text { VAS }\end{array}$} & Pre & $5.60+1.29$ & \multirow[t]{2}{*}{0.001} \\
\hline & & Post & $3.39+1.75$ & \\
\hline & \multirow{2}{*}{$\begin{array}{c}\text { Disability } \\
\text { on ODI }\end{array}$} & Pre & $38.4+11.64$ & \multirow[t]{2}{*}{0.002} \\
\hline & & Post & $21.73+6.58$ & \\
\hline
\end{tabular}

Table 2: Between group analysis of both interventions

Between group analysis of parametric variable (Disability, ROM)

\begin{tabular}{|c|c|c|c|c|}
\hline & Groups & Mean & $\begin{array}{c}\text { Std. } \\
\text { Deviation }\end{array}$ & P value \\
\hline \multirow{2}{*}{$\begin{array}{c}\text { ODI } \\
\text { scale }\end{array}$} & TENS Group & 18.5625 & 4.58939 & \multirow{2}{*}{0.103} \\
\cline { 2 - 4 } & IF Group & 22.5625 & 7.17374 & \\
\hline \multirow{2}{*}{$\begin{array}{c}\text { ROM } \\
\text { angle }\end{array}$} & TENS Group & 82.94 & 6.728 & \multirow{2}{*}{0.413} \\
\cline { 2 - 4 } & IF Group & 77.69 & 7.454 & \\
\hline
\end{tabular}

strong evidence for the null hypothesis. This means that there is no relationship between the two variables.

\section{DISCUSSION}

The results showed that there is no significance difference between the two modalities of treatment i.e. TENS and IF current. Both modalities showed the significant drop in pain intensity, and reduction in disability due to lower back pain on VAS and ODI.

Some recent studies have found positive effects of TENS and IF in chronic low back pain reduction with no significant difference in both modalities ${ }^{10}$. A meta-analysis has concluded that TENS and IF both have similar effect on pain ${ }^{11}$.

A study conducted by Keskin divided pregnant women with LBP into 4 groups. One control group and 3 treatment groups (TENS, exercise and acetaminophen), concluded that TENS is an effective and safe treatment for LBP during pregnancy ${ }^{12}$. Renata Zaniewska analyzed quality of life in patients of LBP treated with TENS concluding that if combined with other treatment methods, may improve quality of life in patients of LBP ${ }^{13}$.

A single-blind randomized controlled trial conducted in physiotherapy department of Centro Universitário de Maringá found no difference between TENS and IF current for chronic low back pain treatment which is compatible to our results ${ }^{14}$. According to Korelo, TENS in combination with other therapeutic exercises is much more effective in patients with $\mathrm{LBP}^{15}$.
A randomized clinical trial was conducted on patients with chronic non-specific LBP, 62 patients were assigned to 2 groups an experimental and control group. Experimental group underwent massage with IF current and the control group received superficial lower back massage. Improvement was noted in patients with acute LBP with IF current electro-massage as compared to superficial massage ${ }^{16}$. A recent Systematic review done by Sukhyanti Kerai, suggest that still further studies are required to compare effect of TENS with other modalities. ${ }^{17}$ Our study has found reduction in pain intensity and overall this study used different therapies, different scales and questionnaires.

The findings showed that TENS and IF current both are effective modalities of treatment in patients with chronic pain in the lower back and there is no difference in both modalities in reduction of pain intensity and decreasing disability due to low back pain. TENS and IF current both are effective mode of treatment but in combination with conservative treatment such as hot pack, produces more significant effect in treating lower back pain, reducing pain intensity and disability. This study is conducted in a single town with small sample size therefore, large scale trails are recommended to authenticate the effectiveness of TENS and IF in patients with LBP.

\section{CONCLUSION}

The results from this study found that TENS and IF current both are effective modalities in reducing pain intensity and decreasing disability in LBP patients. Therefore the use of TENS and IF current along with heating pads should be encouraged in patients with nonspecific low back pain.

\section{REFERENCES}

1. The Effectiveness of Combined Transcutaneous Electrical Nerve Stimulation and Interferential Current Therapy on Chronic Low Back Pain: A Randomized, Double-Blind, Sham-Controlled Study. Journal of Physical Medicine \& Rehabilitation Sciences/Fiziksel Tup ve Rehabilitasyon Bilimleri Dergisi. 2020 Jan 1;23(1).

2. Rampazo da Silva ÉP, Silva VR, Bernardes AS, Matuzawa F, Liebano RE. Segmental and extrasegmental hypoalgesic effects of low-frequency pulsed current and modulated kilohertz-frequency currents in healthy subjects: randomized clinical trial. Physiotherapy Theory and Practice. 2019 Aug 10:1-0..

3. Albornoz-Cabello M, Maya-Martín J, Domínguez-Maldonado G, Espejo-Antúnez L, Heredia-Rizo AM. Effect of interferential current therapy on pain perception and disability level in subjects with chronic low back pain: a randomized controlled trial. Clinical rehabilitation. 2017 Feb;31(2):242-9..

4. Lim SS, Vos T, Flaxman AD, Danaei G, Shibuya K, Adair-Rohani $\mathrm{H}$, et al. A comparative risk assessment of burden of disease and injury attributable to 67 risk factors and risk factor clusters in 21 regions, 1990-2010: 
a systematic analysis for the Global Burden of Disease Study 2010. The lancet. 2013;380(9859):2224-60.

5. Chaparro LE, Furlan AD, Deshpande A, Mailis-Gagnon A, Atlas S, Turk DC. Opioids compared with placebo or other treatments for chronic low back pain: an update of the Cochrane Review. Spine. 2014;39(7):556-63.

6. Thiese MS, Hughes M, Biggs J. Electrical stimulation for chronic non-specific low back pain in a working-age population: a 12-week double blinded randomized controlled trial. BMC musculoskeletal disorders. 2013;14(1):117.

7. de Almeida CC, da Silva VZ, Júnior GC, Liebano RE, Durigan JL. Transcutaneous electrical nerve stimulation and interferential current demonstrate similar effects in relieving acute and chronic pain: a systematic review with meta-analysis. Brazilian journal of physical therapy. 2018 Sep 1;22(5):347-54.

8. Resende L, Merriwether E, Rampazo EP, Dailey D, Embree J, Deberg J, Liebano RE, Sluka KA. Meta-analysis of transcutaneous electrical nerve stimulation for relief of spinal pain. European Journal of Pain. 2018 Apr;22(4):663-78.

9. Ucurum SG, Kaya DO, Kayali Y, Askin A, Tekindal MA. Comparison of different electrotherapy methods and exercise therapy in shoulder impingement syndrome: A prospective randomized controlled trial. Acta orthopaedica et traumatologica turcica. 2018 Jul 1;52(4):249-55.

10. Çıtak Karakaya I, Karakaya MG, Erğun E, Elmalı S, Fırat T. Effects of different frequencies of conventional TENSon pressure pain threshold and tolerance. Journal of back and musculoskeletal rehabilitation. 2014;27(2):197-201.

11. Dohnert M, Bauer J, Pavão T. Study of the effectiveness of IF current as compared to TENSin reducing chronic low back pain. Revista Dor. 2015;16.

12. De Almeida CC, da Silva VZM, Júnior GC, Liebano RE, Durigan JLQ. TENSand IF current demonstrate similar effects in relieving acute and chronic pain: a systematic review with meta-analysis. Brazilian journal of physical therapy. 2018;22(5):347-54.

13. Korelo RIG, Ragasson CAP, Lerner CE, Morais JCd, Cossa JBN, Krauczuk C. Efeito de um programa cinesioterapêutico de grupo, aliado à escola de postura, na lombalgia crônica. Fisioterapia em Movimento. 2013;26(2):389-94.
14. Lara-Palomo IC, Aguilar-Ferrándiz ME, Matarán-Peñarrocha GA, Saavedra-Hernández M, Granero-Molina J, Fernández-Sola $\mathrm{C}$, et al. Short-term effects of IF current electro-massage in adults with chronic non-specific low back pain: a randomized controlled trial. Clinical rehabilitation. 2013;27(5):439-49.

15. Kerai S, Saxena KN, Taneja B, Sehrawat L. Role of TENSin post-operative analgesia. Indian journal of anaesthesia. 2014;58(4):388.

16. Is Interferential current before pilates exercises more effective than placebo in patients with chronic nonspecific low back pain?: a randomized controlled trial. Archives of physical medicine and rehabilitation. 2017 Feb 1;98(2):320-8.

17. Kerai S, Saxena KN, Taneja B, Sehrawat L. Role of transcutaneous electrical nerve stimulation in post-operative analgesia. Indian journal of anaesthesia. 2014 Jul;58(4):388.

CONFLICT OF INTEREST: Authors declare no conflict of interest

GRANT SUPPORT AND FINANCIAL DISCLOSURE: NIL

\section{AUTHOR'S CONTRIBUTION}

Following authors have made substantial contributions to the manuscript as under

Adnan M: $\quad$ Main Idea data collection Manuscript writing

Ali B: $\quad$ Overall supervision and approval of final version

Sajjad MM: References

Rahman A: Statistical Analysis

Qurashi OR: Bibliography

Darain H: Bibliography

Authors agree to be accountable for all aspects of the work in ensuring that questions related to the accuracy or integrity of any part of the work are appropriately investigated and resolved. 